\title{
PARTICIPAÇÃO CIDADÃ LOCAL: REFLEXÕES A PARTIR DA LITERATURA ESPANHOLA SOBRE O TEMA
}

LOCAL CITIZEN PARTICIPATION: REFLECTIONS FROM THE SPANISH LITERATURE ON THE SUBJECT

\author{
Data de submissão: 26/02/2015 \\ Aceite: 19/01/2016 \\ Marcia Prezotti Palassi ${ }^{1}$ \\ Alfredo Rodrigues Leite da Silva² \\ Rogerio Zanon da Silveira ${ }^{3}$
}

\section{RESUMO}

Este ensaio teórico se orienta pela seguinte pergunta: como as contribuições teóricas obtidas da experiência espanhola sobre o tema da participação cidadã contribuem para a compreensão da articulação do protagonismo popular na condução de políticas públicas e sociais locais? O objetivo é identificar e discutir contribuições da experiência espanhola para o desenvolvimento do tema participação cidadã local. Os resultados evidenciam uma profusão de ideias que habitam diferentes visões do que vem a ser participar como cidadão em determinada localidade. Essas ideias permitem associar a participação cidadã local à mudança da realidade social; à integração da participação na gestão; à valorização de aspectos históricoculturais locais e expressões minoritárias; ao estabelecimento de relações horizontais e de confiança; à relativa complementação do sistema representativo; à vigília a ideias de dominação e exclusão que possam permeá-la; à prática de forma individual e coletiva; à precedência a tipos de gestão e modos pessoais de gestão; e ao planejamento, organização e definição de orçamento para que ela funcione.

Palavras-chave: Participação; Cidadania; Administração Pública Local.

\footnotetext{
1 Possui graduação em Administração de Empresas pelo Centro Superior de Ciências Sociais de Vila Velha, UVV, mestrado em Psicologia pela Universidade Federal do Espírito Santo, UFES e doutorado em Psicologia pela Pontifícia Universidade Católica de São Paulo, PUC/SP. Vitória. Espírito Santo. Brasil. E-mail: mprezotti@hotmail.com

2 Possui graduação em Administração pela Faculdade Espírito Santense de Administração, FAESA, mestrado em Administração pela Universidade Federal do Espírito Santo, UFES e doutorado em Administração pela Universidade Federal de Minas Gerais, UFMG. Vitória. Espírito Santo. Brasil. E-mail: alfredoufes@gmail.com.

3 Possui graduação em Ciências Contábeis pela Universidade Candido Mendes, UCAM, mestrado em Ciências Contábeis pelo Instituto de Ensino Superior Prof. Nelson Abel de Almeida, IESNA, mestrado em Administração pela Universidade Federal do Espírito Santo, UFES e doutorado em Administração pela Universidade Federal de Minas Gerais, UFMG. Vitória. Espírito Santo. E-mail: rsilveira@sefaz.es.gov.br
} 


\begin{abstract}
This theoretical essay is oriented by the following question: How can the Spanish experience obtained from theoretical contributions on the topic of citizen participation contribute to the understanding of the articulation of the popular role in the conduct of public and local social policies? The goal is to identify and discuss contributions of the Spanish experience to the development of local citizen participation theme. The results show a profusion of ideas that inhabit different visions of what comes to be participating as a citizen in a given locality. These ideas allow you to associate local citizen participation: change of social reality; integration of participation in management; local cultural-historical values and minority expressions; horizontal relations and reliable; on completion of the representative system; waking the ideas of domination and exclusion that can permeate it; his practice of individual and collective form; precedence types of management and personal modes of management; and planning, organization and budget definition for it to work.
\end{abstract}

Keywords: Participation; Citizenship; Local Public Administration.

\title{
1 INTRODUÇÃO
}

A participação cidadã pode ser entendida como uma "garantia virtual para o êxito de todo tipo de políticas, programas e projetos de desenvolvimento" (CHAVEZ, 2011, p. 37, tradução nossa). Ela é decorrente da transformação de um sistema ditatorial para um sistema democrático e da complementaridade entre a democracia representativa e a participativa. Para Marchioni (2006), a participação cidadã é um elemento fundamental de qualquer mudança social. Por isso, está relacionada a modelos de Estado, cultura política, cidadania, desenvolvimento, governança, governabilidade e descentralização. $O$ estudo de tais relações se tornou mais relevante na medida em que ocorreram reformas estruturais do setor público no mundo, notadamente nas décadas de 1970 e 1980, com a consequente diminuição do Estado de bem-estar social, o crescimento do neoliberalismo e a diminuição do papel do Estado.

Esses fatos fizeram com que, em alguns países, as instâncias regionais e locais assumissem um papel protagonista na condução das políticas públicas e sociais locais. Entre esses países, este ensaio se volta para as contribuições advindas da experiência espanhola. A relevância deste trabalho está na busca por contribuir com interessados em discutir o significado da participação na esfera pública em determinada localidade, vislumbrando que esse entendimento gera orientação para novas experiências, ideias e abordagens teóricas adequadas à realidade social e à política contemporânea. As discussões se baseiam no seguinte problema de pesquisa: como aportes teóricos obtidos a partir da experiência espanhola sobre a participação cidadã contribuem para a articulação do protagonismo popular na condução de políticas públicas e sociais locais? O objetivo é identificar e discutir contribuições da experiência espanhola para o desenvolvimento do tema participação cidadã local.

Por que a experiência espanhola? Além de uma história milenar, a consolidação do Estado espanhol democrático ocorreu contemporaneamente, a partir dos anos 1970, e foi precedida de turbulências políticas e sociais intensas no século XIX. A primeira e curta experiência republicana espanhola ocorre de 1873 a 1874, período marcado por instabilidade social, guerra civil e violência. Em dezembro de 1874, a monarquia é restaurada e dura até 1931, ano em que foi declarada a Segunda República e aprovada a Constituição da República Espanhola. Em 1936, uma tentativa de golpe militar tem como consequência a instauração de guerra civil que só terminou em 1939, culminando com a vitória dos militares (SALVADÓ, 2008). A Espanha estava transtornada. Sobre a quantidade de mortos, estudiosos divergem. Entre os historiadores, há relativo consenso de que estão entre 200 e 400 mil mortos, combatentes e civis. Mas há quem fale em 
1 milhão e em milhões de desaparecidos. Isso sem se considerar os reflexos desses números na sociedade e as centenas de milhares de espanhóis refugiados. A perseguição a religiosos dá ideia das atrocidades cometidas, com destruição de milhares de igrejas e assassinato de milhares de religiosos: padres, freiras, bispos (MONTERO, 1961).

Eis o longo desafio à participação cidadã espanhola. Em 1939, inicia-se o franquismo, ditadura de 36 anos, comandada pelo general Francisco Franco, que foi encerrada em 1975, com a morte de Franco. A transição para a democracia levou seis anos, com a vitória, em 1982, do Partido Socialista Obrero Español (PSOE), com Felipe González, que governou o país até o ano de 1996, com a vitória do PSOE em quatro eleições consecutivas (CARR, 1983). A fundação do PSOE deu-se clandestinamente, em 1879, em torno de um núcleo de intelectuais e trabalhadores, na grande maioria tipógrafos, encabeçados por Pablo Iglesias. Foi um dos primeiros partidos socialistas fundados na Europa (PSOE, 2015).

Esse conturbado contexto secular foi o berço da construção de um leque amplo de experiências de participação cidadã, que acabou gerando uma literatura vasta sobre o tema na literatura espanhola, especialmente a partir da década de 1980. Esse quadro influenciou na escolha da experiência espanhola para o desenvolvimento das reflexões aqui apresentadas.

A partir do problema de pesquisa, este ensaio pretende contribuir para o conjunto de estudiosos interessados na integração da participação cidadã e gestão pública, com foco em alterações do quadro de exclusão social local, como defende Bava (2002). Essa contribuição se legitima quando se considera que a mudança social, se não depende apenas da participação, passa necessariamente por ela. Neste ensaio se defende, concordando-se com Chavez (2011), que as iniciativas de desenvolvimento local relacionadas à gestão pública e baseadas em enfoques participativos produzem melhores resultados do que aquelas fincadas somente em decisões burocráticas, paternalistas ou autoritárias. Lengler (2008) considera que a criação e o desenvolvimento de pequenas associações de produtores também são estratégias capazes de contribuir com a geração de empregos, o desenvolvimento e crescimento econômico regional, mas para isso ocorrer o comportamento dos associados precisa mudar, pois há pouca participação deles nas atividades e nos processos decisórios das associações. Para desenvolver esta discussão, além desta introdução, este ensaio contém um tópico voltado à pluralidade do conceito de participação cidadã local, outro que aborda a literatura e a experiência espanhola em torno dessa temática e, por fim, as considerações finais.

\section{PARTICIPAÇÃO CIDADÃ LOCAL: UM CONCEIŢO PLURAL E DIVERSO}

Entre os múltiplos conceitos de participação cidadã, algumas definições centram-se na relação entre instituições públicas e cidadãos. Existem interpretações de que a participação cidadã é um processo de tomada de decisões birrelacional, criado pelas instituições públicas para estabelecer uma relação com o cidadão, pautando-se no princípio da coparticipação (GRAMBERGER, 2006), ou, de forma mais direta, participação produzida por mecanismos propostos pelos governos municipais (NAVARRO; CUESTA; FONT, 2009).

Pode-se observar que se trata de acepções de participação cidadã fundadas em significados associados à heteronomia, pois nesses conceitos há o sentido de que a participação é algo concedido ou de iniciativa dos que exercem poderes institucionais. A participação é, assim, "criada pelo poder institucional" ou viabilizada a partir de "mecanismos propostos" pelo poder institucional. Outro foco dado ao entendimento da participação cidadã é tratá-la como um pro- 
cesso útil para complementar o sistema representativo de governo. Brugué (2007), por exemplo, vê a participação como uma forma de tomar decisões na gestão pública e discutir problemas que necessitam da opinião dos cidadãos, reforçando os mecanismos atuais de desenvolvimento da democracia. Borrel (1998) também se alinha a esse pensamento, ao apresentar a participação cidadã como um conjunto de técnicas que possibilitam a intervenção dos cidadãos na administração pública sem se integrar em estruturas burocráticas. Em uma ótica que se relaciona com a gestão pública, mas foca um elemento adicional, Bergantiños, Ibarra e Martinez (2011) avançam no sentido de atrelar o tema da participação cidadã com a política. Os autores tratam de instrumentos diversificados ou procedimentos participativos, geralmente aplicados nas instituições municipais, ou de cidadãos organizados para deliberar e propor soluções coletivas relativas a conflitos específicos ou projetos políticos.

Também no que tange à política, Chavez (2011, p. 37, tradução nossa) entende a participação cidadã como um processo voltado à mudança politicamente articulada, conceituando-a da seguinte maneira: "um processo político que implica necessariamente a aplicação de profundas reformas institucionais e, como se poderia esperar, processo que gera diferentes tipos e graus de oposição e apoio de muitos setores sociais, políticos e econômicos". Essa articulação entre participação cidadã, mudança e política oferece espaço para se incluir outro aspecto considerado relevante, o desenvolvimento local. Conforme defende Pindado (2012), a participação cidadã deve ser compreendida como um conjunto de ações ou iniciativas relativas à democracia participativa para impulsionar o desenvolvimento local através da incorporação da comunidade à política. Alguns aspectos chamam a atenção na acepção desenvolvida por Pindado (2012), por parecerem mais próximos aos valores de autonomia e política, como se fossem "iniciativas", que podem partir tanto da "comunidade" quanto da instituição. Essa percepção compreende a participação cidadã como ação no sentido de "incorporação da comunidade à política", e não à representação política, como aparece preponderantemente nos conceitos sobre o tema.

Também com foco na concepção de comunidade, a discussão conceitual sobre participação cidadã se volta para as relações entre os membros dessa comunidade ao incorporar a temática dos valores culturais. Nessa direção, Geli (2011), baseando-se nas comunidades indígenas de Michoacán e da Araucanía, que compõem uma rede familiar-local de mapuches, chilenos e descendentes de colonos europeus, mantém os princípios da participação cidadã já discutidos. Além disso, incorpora os valores relativos às relações sociais entre grupos culturalmente diferentes. Dessa maneira, o autor propõe que sejam gerados cenários pautados no respeito, no reconhecimento, na legitimação e nas relações horizontais, considerando as condições históricas de desigualdade. Todavia, a participação cidadã abrange comportamentos participativos que podem ter conotação política ou não. Nesse sentido, Morales (2005) estabelece diferenças entre a participação cidadã e política. A participação cidadã abrange e inclui a participação em associações que não são políticas, ou seja, associações fora da abrangência das instituições político-democrático-representativas. Já a participação política só se refere a ações que têm influência na tomada de decisões no campo político-institucional, ou seja, no campo da representação político-institucional.

Essas e outras contribuições aqui articuladas são sintetizadas por Falck e Yáñez (2011), ao apontarem que o conceito de participação presente em grande parte dos artigos e pesquisas envolve a possibilidade de intervenção dos cidadãos na política, compreendendo, refletindo, decidindo, fiscalizando, comportando-se como cidadãos informados e dispostos, responsabilizando-se junto com as instituições na gestão pública e de seus próprios territórios e comunidades. Os autores revelam o caráter amplo e difuso do conceito ao confrontar as publicações. Os próprios autores indagam sobre qual seria o verdadeiro sentido da participação. Até onde ele deve chegar? Como 
deveria ocorrer sua operacionalização? Quais os custos de sua aplicação? Trata-se de um mecanismo de transformação social? Seus mecanismos são amplos, universais, inclusivos ou uma pseudoparticipação? A transparência propagada em discursos possui caráter apenas procedimental, sem pretensões de mudanças nas instituições públicas e na atuação política? O conjunto de questões colocadas por Falck e Yáñez (2011) parece ser tão amplo quanto a própria concepção de participação cidadã. No sentido de discutir parte desses aspectos, a seguir são apresentados estudos de autores que se baseiam em experiências espanholas de participação cidadã.

\section{A PARTICIPAÇÃO CIDADÃ SOB A PERSPECTIVA DA EX- PERIÊNCIA ESPANHOLA}

O significado da participação cidadã em diferentes instituições é ponto de partida para um estudo de Chavez (2011), que chama a atenção para o fato de a dinâmica da dominação e exclusão permanecer em comunidades e em espaços supostamente participativos. Isso porque os mecanismos participativos, frequentemente, não incluem as comunidades ou sujeitos historicamente vulneráveis e marginalizados. Trata-se de uma crítica à representação política, discussão que aparece frequentemente na literatura sobre participação cidadã. Chavez (2011) vai de encontro à ideia de representação como vontade da maioria. $O$ autor expressa que os representantes das comunidades deveriam atuar diante das autoridades ou dos profissionais da gestão pública, de forma a preservar aspectos relativos à diversidade das comunidades representadas, como gênero, origem étnica, classe, orientação político-ideológica, idade, nacionalidade, orientação sexual etc. Enfim, respeitar as características identitárias, para que o desenvolvimento de práticas participativas seja significativo para as comunidades, em vez de voltar-se apenas para melhorar a eficiência e eficácia da administração pública.

Sobre a relação entre participação e gestão, Chavez (2011) identifica que poucos acadêmicos, políticos, analistas, conservadores, organismos multilaterais de desenvolvimento, movimentos políticos e sociais radicais e pensadores progressistas questionam a relevância da participação cidadã na gestão pública. Poucos também questionam o poder democratizante da participação, seja em nível nacional, seja regional ou local. Porém, por detrás desse aparente consenso, ocultam-se muitos e profundos desacordos políticos, segundo o autor. Participação cidadã pode significar uma clara transferência de poder e capacidade para a tomada de decisões ou uma mera consulta. Pode também assumir uma perspectiva puramente instrumental, transformandose em uma força regressiva, contínua. Geli (2011) considera que os espaços participativos tornam ainda mais complexos o conceito e o significado da participação cidadã, principalmente em um contexto de globalização capitalista ou neoliberal, cuja participação cidadã pode se dar tanto nos mecanismos participativos instituídos pela administração pública local como em espaços informais. Chavez (2011) alerta que, por detrás dos significados, encontram-se diferentes intenções, muitas vezes opostas, o que requer cuidado na utilização desse conceito, já que existem diversas formas e níveis de participação.

A oferta de oportunidades de participação pode se dar no âmbito global, setorial, temático, territorial ou local. Segundo Chavez (2011), no âmbito local, verifica-se nas últimas décadas um crescimento da oferta de oportunidades de participação nas prefeituras espanholas, por meio de mecanismos participativos institucionais, também chamados de canais, estruturas, ferramentas, processos e espaços participativos (ainda que haja conceituações diferentes para cada um desses termos). Pode-se citar, como exemplo, o orçamento participativo, o planejamento estratégico participativo, os conselhos gestores de políticas públicas etc. A adoção desses 
mecanismos tem se tornado uma prática comum em muitos municípios, em diferentes países, sendo implantados de formas diferentes.

A implantação de mecanismos de participação não basta. É preciso divulgá-los para que os cidadãos possam conhecê-los e compreendê-los. Na Espanha, Navarro, Cuesta e Font (2009) constatam baixa porcentagem da população que os conhece. Além disso, a participação cidadã nestes mecanismos encontra-se nos níveis de informação e consulta, considerando as associações e os próprios cidadãos como os maiores defensores dos seus interesses, em vez da classe política local. Isso porque, além do âmbito da participação, há também o nível de participação permitido pela administração pública local, que pode variar de informativo a consultivo, até chegar ao nível mais alto, o de gestão compartilhada (BONETT, s.d.). É possível perceber que o sentido da participação está, em grande parte dos estudos, associado a iniciativas originárias da representação. Essas iniciativas podem ser realizadas com intenções diferentes, ora como vontade oriunda da representação de realmente fomentar a participação e criar canais que aproximem gestão pública e cidadão, ora com o intuito de praticar uma pseudorrepresentação. No entanto, a participação cidadã não se restringe aos mecanismos participativos nas instituições representativas, pois existem iniciativas cidadãs, como práticas de autogestão de espaços públicos, que são realizadas à margem do âmbito institucional, pautadas em acordos com a administração, obtendo diferentes resultados segundo os casos e conjunturas que originam tais iniciativas, como chamam a atenção Barbarrusa et al. (2011).

Dessas possibilidades de articulação surgem diferentes tipos de participação, que têm sido objeto de pesquisa de muitos autores. Por exemplo, Navarro, Cuesta e Font (2009) oferecem contribuições para a avaliação das preferências dos cidadãos por tipos de mecanismos participativos, a partir da proposição das seguintes categorias: descentralização (se as prefeituras fomentam processos de tomada de decisões nos bairros); orçamento participativo (se organizam assembleias sobre o gasto municipal); pesquisas sobre temas específicos (se as adotam visando conhecer a opinião dos cidadãos); assembleias (se as organizam para obter ou prestar informações necessárias à execução de projetos); publicação dos objetivos dos serviços prestados pelas prefeituras; conselhos consultivos (se os criam reunindo empresas, sindicatos, organizações da sociedade civil etc.); uso da internet nos municípios (se o proporcionam para facilitar o acesso à informação); entre outras que possam ser relevantes conforme as especificidades locais e os objetivos pretendidos. Outra tipologia proposta por Navarro (2000) diferencia os tipos de municípios em inovadores ou imitadores e foi obtida quando o autor analisou experiências de aprovação de normas ou do Regulamento de Participação Cidadã (RPC) na Espanha. Municípios inovadores são aqueles que criam e operacionalizam processos participativos antes de serem obrigados a fazê-lo devido a normas. Já os municípios imitadores são aqueles que implantam processos participativos baseados em experiências desenvolvidas nos municípios inovadores e após exigências legais ou normativas. $O$ autor comprova que a colaboração entre governo municipal e associações locais é menor nos municípios imitadores, de menor tamanho e administrados por partidos nacionalistas e conservadores.

Como na visão de Navarro, Cuesta e Font (2009), esses contextos se caracterizam como trava participativa, falácia participativa, impulso participativo, politeya participativa e abertura participativa. Seria essa, então, uma espécie de contexto local não participativo. Essa discussão desenvolvida pelos autores permite compreender porque os cidadãos optam por participar ou não, ao analisarem o grau de implicação na participação local nos mecanismos participativos na Espanha. Segundo os autores, a maioria dos cidadãos não participa devido ao baixo conhecimento dos mecanismos (seja devido ao pouco esforço das prefeituras para divulgá-los, seja porque 
os cidadãos estão pouco atentos a esse tipo de informação). Cabe aqui uma reflexão: a de que o desconhecimento parece não ter força explicativa, uma vez que os autores encontraram cidadãos que conhecem os mecanismos e nunca participaram.

Navarro, Cuesta e Font (2009) também investigaram um fator que pode ter influência, ainda que limitada, na participação, que é a desconfiança na eficácia dos mecanismos. Embora alguns cidadãos utilizem essa justificativa, a confiança na eficácia dos mecanismos participativos é razoavelmente alta entre os demais e entre aqueles que os conhecem, valorizando-os melhor do que o restante da população, ainda que possa haver variações e situações inversas de um município para outro. A desconfiança atua contra a participação de algumas pessoas, porém não parece ser um fator explicativo fundamental nos resultados das pesquisas desses autores. A maioria das pessoas alega não ter participado porque não precisa, seguida por aquelas que dizem não ter tempo. Para Navarro (2008), a principal razão da falta de implicação daqueles que conhecem e não participam é de tipo instrumental, que se refere a não ter tempo ou não necessitar. Ou seja, a falta de participação não se trata de um desinteresse pelos assuntos públicos e de um afastamento da esfera pública, mas da percepção de ausência de benefícios em comparação com o esforço exigido para participar. Segundo Navarro, Cuesta e Font (2009), os cidadãos que participam nos mecanismos participativos ofertados pelas prefeituras apresentam perfil parecido com aqueles que participam em outros espaços, como votar nas eleições, recolher assinaturas ou pertencer a associações, principalmente associação de moradores. Trata-se de "participantes" que têm a visão de participação como um valor, necessidade da organização da vida em sociedade.

Essa questão vai ao encontro da discussão sobre quais ações ou iniciativas pessoais podem ser compreendidas como participação cidadã. Para tratarem desse aspecto, Navarro, Cuesta e Font (2009) estudaram diversas atitudes consideradas modalidades de atividade política, que podem ser entendidas como ações participativas cidadãs. Os autores citam: contato com o vereador, prefeito ou funcionário ou empregado da administração municipal; queixa e reclamação na prefeitura; contato com uma associação; doação de dinheiro para uma organização; contato com um meio de comunicação social; participação em ações coletivas diversas, seja presencial, como manifestações e greves, seja virtual, como participação em fóruns ou grupos de discussão na internet; assinatura de petições e tentativa de mobilização de outras pessoas para divulgá-las e assiná-las; participação em um partido político e colaboração com as ações do partido no município. Para os autores, dois procedimentos predominam na disseminação de mensagens de baixo para cima: os contatos administrativos com funcionários ou empregados da administração municipal para tentar resolver problemas; e as ações inerentes ao protesto suave (assinatura de petições) e ao protesto de caráter mais enfático (como as manifestações e greves relativas a um problema local).

As associações, com diferentes características e objetivos, exercem impacto na participação cidadã. Warren (2001) ressalta a relevância das associações, pois elas promovem o sentimento de pertença associativa ao gerar diferentes tipos de implicação associativa, como a implicação política interna (participar de reuniões e assembleias organizadas pelas associações); implicação política externa (participar de manifestações, protestos, assinaturas em petições das associações); e implicação para o consumo de serviços associativos (participar em atividades recreativas ou de formação organizadas pelas associações), promovendo efeitos democráticos e de resistência.

É possível ainda associar o legado histórico-cultural de uma localidade às características e à intensidade da participação de seus habitantes. Observando a realidade de cada cidade pesquisada na Espanha, Navarro (2008) e Navarro, Cuesta e Font (2009) identificam diferenças entre elas e um padrão segundo o qual a participação cidadã contribui para mostrar traços principais de cada cidade ou modelo participativo que elas desenvolvem, supondo que contextos participativos 
provocam mais implicação dos cidadãos por oferecerem diversas oportunidades de participação, contribuindo para aumentar a participação cidadã. Em sentido parecido, Geli (2011) comenta que a integração das pessoas em um processo participativo revela reflexos da realidade social do seu entorno, mostrando as barreiras existentes e gerando trabalho para as equipes dinamizadoras da participação, para eliminá-las. A forma de gestão adotada pelos gestores públicos de determinada localidade influencia na característica e na intensidade da participação cidadã. Essa forma de gestão pode estar mais próxima à ideia do cidadão como consumidor de bens e serviços públicos. Outros gestores podem preferir buscar uma maior proximidade com os cidadãos, em uma espécie de associação entre população e gestão. Essa relação é estudada por Chavez (2011, tradução nossa). Segundo o autor, a relação entre a preferência por um tipo de governança local e os mecanismos participativos insere-se numa lógica contextual da participação cidadã.

Entretanto, conforme Navarro, Cuesta e Font (2009), os contextos parecem ter menos influência que as atitudes inerentes à democracia local na configuração da opinião pública, pois os resultados das pesquisas apontam que a preferência por determinado mecanismo participativo parece ser anterior ou independente do contexto. Os autores verificam que os cidadãos que preferem a governança local consumerista são menos implicados politicamente e têm uma "lógica econômica" da democracia, em que a transparência, a possibilidade de apresentar demandas e prestar contas é desejada, mas sem demandar a participação cidadã ativa nos processos políticos, centrando atividade no voto, preferindo o modelo de democracia local eleitoral. Cidadãos que preferem a governança local associativa têm uma lógica de representação mais próxima da política municipal, pautada no ativismo associativo, por meio de processos de descentralização ou de atores e associações mais próximas das prefeituras.

Outro aspecto que pode interferir na preferência dos mecanismos de participação tem a ver com os objetivos que são propostos por meio de diferentes mecanismos. Nesse sentido, Fuente (2010) afirma que a participação cidadã agrupa práticas heterogêneas voltadas para objetivos extraordinariamente diversos, como são os objetivos políticos, gerenciais e sociais, conforme exposto nos Quadros 1, 2 e 3, a seguir.

Quadro 1. Objetivos políticos dos mecanismos participativos

\begin{tabular}{|c|c|}
\hline CARACTERÍSTICAS & AUTORES \\
\hline Igualdade e cidadania & $\begin{array}{c}\text { Observatorio Internacional de } \\
\begin{array}{c}\text { Ciudadanía y Medio Ambiente } \\
\text { Sostenible (Cimas) (2012) }\end{array}\end{array}$ \\
\hline $\begin{array}{l}\text { Participação como um dos pilares da ideia de democracia e dos critérios } \\
\text { para julgamento da ação governamental pelos cidadãos; } \\
\text { Estímulo para impulsionar a transparência na gestão pública: uma espécie } \\
\text { de escola democrática tanto para os governantes como para a cidadania. }\end{array}$ & Fuente (2010) \\
\hline Alternativa para melhorar a qualidade da democracia. & $\begin{array}{l}\text { Fernández, Olivari e Yáñez } \\
\text { (2011) }\end{array}$ \\
\hline $\begin{array}{l}\text { Possibilidade de os políticos adotarem decisões mais próximas às expec- } \\
\text { tativas dos cidadãos. }\end{array}$ & Seller (2008) \\
\hline Momentos e dinâmicas de deliberação pública cidadã. & Navarro, Cuesta e Font (2009) \\
\hline $\begin{array}{l}\text { Possibilidade de superação do déficit democrático nas instituições repre- } \\
\text { sentativas. }\end{array}$ & Subirats (2001) e Fuente (2010) \\
\hline Alternativa para articulação das ações governamentais. & Morais (2011) \\
\hline $\begin{array}{l}\text { Discurso político favorável à formação de técnicos na gestão de metodo- } \\
\text { logias participativas; } \\
\text { Apoio financeiro e logístico ao desenvolvimento de processos de inova- } \\
\text { ção democrática. }\end{array}$ & Font e Blanco (2005) \\
\hline $\begin{array}{l}\text { Estabelecimento de novas relações com os cidadãos devido à diminuição } \\
\text { da participação eleitoral. }\end{array}$ & Gramberger (2011) \\
\hline
\end{tabular}

Fonte: elaborado pelos autores. 
Em paralelo aos objetivos políticos, encontram-se os objetivos gerenciais e sociais. Os objetivos gerenciais estão listados no Quadro 2, adiante.

Quadro 2. Objetivos gerenciais dos mecanismos participativos

\begin{tabular}{|l|c|}
\hline \multicolumn{1}{|c|}{ CARACTERÍSTICAS } & \multicolumn{1}{|c|}{ AUTORES } \\
\hline $\begin{array}{l}\text { Melhorar a eficiência e a eficácia da atividade governamental e adminis- } \\
\text { trativa. }\end{array}$ & Brugué (2008) e Cimas (2012) \\
\hline Melhorar a governabilidade. & Biagioni e Alemany (2011) \\
\hline $\begin{array}{l}\text { Progressiva adequação do funcionamento das instituições; } \\
\text { Oferta de ferramentas para avaliar e melhorar a gestão dos assuntos pú- } \\
\text { blicos e as condições de vida. }\end{array}$ & Seller (2008) \\
\hline $\begin{array}{l}\text { Melhorar a gestão urbana; } \\
\text { Promover intercâmbio entre grupos sociais e cidadãos para viabilizar so- } \\
\text { luções e decisões; } \\
\text { Lutar contra a exclusão; } \\
\text { Antecipar conflitos. }\end{array}$ & \\
\hline $\begin{array}{l}\text { Proporcionar aos dirigentes melhores fundamentos para a tomada de de- } \\
\text { cisões; } \\
\begin{array}{l}\text { Permitir que a sociedade reúna um conjunto de recursos para enfrentar } \\
\text { numerosos problemas atuais de governabilidade. }\end{array}\end{array}$ \\
\hline $\begin{array}{l}\text { Corresponsabilizar agentes-chave para o bom desenvolvimento de políti- } \\
\text { cas públicas. }\end{array}$ & Framberger (2011) \\
\hline
\end{tabular}

Fonte: elaborado pelos autores.

Já os objetivos sociais podem ser vistos no Quadro 3, a seguir.

Quadro 3 Objetivos sociais dos mecanismos participativos

\begin{tabular}{|c|c|}
\hline CARACTERÍSTICAS & AUTORES \\
\hline Confiança. & Cimas (2012) \\
\hline $\begin{array}{l}\text { Solução para o desafeto político; } \\
\text { Criação de vínculos de relacionamento interpessoal; } \\
\text { Coesão, geração de capital social, integração social dos excluídos. }\end{array}$ & Fuente (2010) \\
\hline Geração de vida associativa. & Font et al. (2000) \\
\hline $\begin{array}{l}\text { Reconquista do espaço público; } \\
\text { Potencialização de sentimentos comunitários; } \\
\text { Rompimento da apatia, da indiferença e da desconfiança cidadã; } \\
\text { Bem-estar e melhoria das condições sociais dos coletivos representados; } \\
\text { Estreitamento de laços de colaboração com os serviços sociais municipais; } \\
\text { Promoção do conhecimento das necessidades de outros coletivos; } \\
\text { Reconhecimento das dificuldades da gestão dos assuntos públicos. }\end{array}$ & Seller (2008) \\
\hline $\begin{array}{l}\text { Contribuição para promover a confiança política entre os distintos atores políticos e } \\
\text { coletivos sociais de uma localidade. }\end{array}$ & $\begin{array}{l}\text { Font e Blanco } \\
(2005)\end{array}$ \\
\hline $\begin{array}{l}\text { Possibilidade de as pessoas participarem das decisões que afetam a sua vida, con- } \\
\text { ferindo dignidade e autoestima, que são elementos essenciais para a felicidade e o } \\
\text { bem-estar. }\end{array}$ & Geli (2011) \\
\hline Direito humano básico que faz parte do desenvolvimento humano. & Pnud (2002) \\
\hline
\end{tabular}

Fonte: elaborado pelos autores.

Os obstáculos para atingir esses objetivos são inúmeros, caracterizando a participação cidadã como um processo em construção e em desenvolvimento, que, após ter ampliado os espaços participativos, requer agora dedicação para seu aperfeiçoamento e evolução. Adotando as mesmas categorias propostas por Fuente (2010) para a classificação dos objetivos da participação, pode-se afirmar que há obstáculos políticos, gerenciais e sociais. Os obstáculos políticos e gerenciais estão associados às instituições representativas e suas estruturas e gestão. Os obs- 
táculos sociais podem ser visualizados na baixa participação dos cidadãos; na falsa dicotomia representação e participação (FUENTE, 2010); na falta de representatividade dos participantes nos mecanismos participativos que demandam representação (FONT et al., 2000); na delegação passiva da cidadania aos representantes dos partidos em todos os níveis do sistema político e institucional (MARCHIONI, 2006); e no desafeto institucional que se refere a baixos níveis de confiança nas instituições, nos mecanismos de representação democrática e em seus representantes, embora apoiem o regime democrático, cuja crítica não significa necessariamente um aspecto negativo, pois pode servir para dinamizar a vida democrática (TORCAL, 2006).

Para além desses e outros obstáculos, é necessário abordar as próprias limitações do processo de participação. Ou seja, se não bastassem os obstáculos, a participação cidadã também tem suas limitações administrativas (BONETT, s.d.), de tempo, de recursos educativos, de interesse dos cidadãos, de variabilidade, de representatividade (FUENTE, 2010), de legitimação das autoridades políticas, relativas ao fenômeno "nimby", de controle dos efeitos da participação, de caráter consultivo e associativo (FONT et al., 2000). De forma geral, as limitações relativas à representatividade podem ser vistas na criação de uma linha paralela de representantes dos cidadãos em relação aos representantes eleitos no processo eleitoral da democracia representativa, porta-vozes de interesses particulares (territoriais, sociais ou setoriais) e com legitimidade duvidosa para representar a cidadania em sua totalidade (FUENTE, 2010).

Já foi falado sobre o tipo de gestão adotado e sua influência na participação cidadã. Mesmo adotando-se um tipo ou outro, há ainda o estilo pessoal do gestor ou da equipe no exercício do comando. Segundo Barbarrusa et al. (2011), o estilo de gestão municipal é outro elemento que facilita ou dificulta a participação cidadã, pois condiciona o desenvolvimento de programa ou iniciativa nas prefeituras, podendo variar em diferentes instâncias dentro de uma prefeitura e entre elas em um mesmo estado de um país, assim como pode permanecer ou mudar a cada eleição dos governantes. Os modelos de gestão populistas dificultam a participação cidadã porque o conceito de público não está suficientemente desenvolvido. São impostos interesses particulares na competição pelo acesso aos recursos públicos, e participar no setor público está relacionado a desenvolver estratégias particulares.

Os modelos de gestão técnico-gestionista também não são adequados, porque a participação cidadã é vista como consumo de serviços públicos. Participar significa assistir ao poder político-técnico organizar as necessidades de todos. O modo de gestão defendido por Barbarrusa et al. (2011) é o cidadanista, porque faz referência à participação em cada espaço, reinventando o modo de organização social, desde práticas cotidianas, permitindo a definição de papéis sociais conforme o tempo e espaço. Possibilita desempenhá-los em diferentes situações e relações simétricas, considerando os conhecimentos válidos em um momento, independentemente de serem provenientes de estudos e habilidades ou de serem reconhecidos pela ciência, respeitando o poder de convencimento dos demais independente de exercerem ou não um posto de representatividade política. Diante de tantas polêmicas, obstáculos e limitações, surgem propostas de princípios, conselhos, ações para democratizar a administração e organizar a participação local. Gramberger (2006) cita os princípios e os conselhos propostos pela Organização para a Cooperação e o Desenvolvimento Econômico (OCDE) para melhorar a informação, a consulta e a participação ativa da cidadania no processo de decisão. Na OCDE, entende-se que princípios como compromisso, direito, clareza, calendário, objetividade, recursos, coordenação, obrigação em prestar contas, avaliação e cidadania ativa são princípios que, se não forem colocados em prática, inviabilizam o êxito da participação cidadã.

Além desses princípios, o autor sugere reforçar as relações entre as instituições públicas e os cidadãos através de um conjunto de ações: tratar o assunto com seriedade; situar-se sob o 
ponto de vista dos cidadãos; cumprir promessas; cuidar do fator tempo; ser criativo; administrar conflitos de interesse; preparar-se para receber críticas; envolver os colaboradores; adotar uma política coerente; e atuar imediatamente, ou seja, prevenir antes de curar. Tais ações se alinham com o entendimento de que a informação, consulta e participação ativa constituem os pilares da influência dos cidadãos nos processos de tomada de decisões. Tal influência não invalida a aplicação de regras formais e princípios da democracia, como as eleições, assembleias, gestores responsabilizados por seus atos, pluralismo, respeito aos direitos humanos etc. (GRAMBERGER, 2006). Nessas discussões, é possível separar propostas tendentes à real democratização da administração daquelas voltadas à organização da participação local. Propostas para a democratização da administração podem ser entendidas como críticas à administração. Seller (2008) ressalta que um modelo centrado no institucional, com procedimentos previstos e controlados pela e para a administração, com um desenho que introduz assimetrias nas oportunidades de participação, incluindo e excluindo cidadãos em função de interesses eleitorais, é uma democratização parcial e enviesada, que reforça a dependência das organizações sociais em relação à administração.

Subirats (2002) defende a necessidade de reestruturação das instituições públicas para eliminar a mistura de inércia institucional, visão imediata e aversão a riscos das elites políticas que mantêm o distanciamento entre sociedade e política, a fim de estabelecer uma nova maneira de governar que distribua poder e responsabilidade e considere as pessoas seres inteligentes e implicados. Gramberger (2011) aponta que os governos podem governar sem considerar as preocupações e a participação dos cidadãos, provocando crises de confiança, ou governar com abertura às preocupações e participação dos cidadãos, elaborando políticas públicas de melhor qualidade, beneficiando-se com o aumento da confiança cidadã, obtendo legitimidade e exercendo papel por meio de melhores fundamentos para a tomada de decisões.

Fuente (2010) opina que o desenvolvimento e implantação de instrumentos participativos tanto seduz como atemoriza os ocupantes de cargos eletivos. Isso gera uma posição ambígua, pois favorece a sua implantação, mas tenta limitar e controlar a influência dos cidadãos nas decisões, implantando-os quando necessitam justificar decisões tomadas ou ignorar a opinião do público diante da ameaça de continuidade de um projeto, ou quando precisam superar obstáculos da democracia representativa. As propostas para a organização da participação local podem ser vistas como sugestões para superar as dificuldades encontradas até o momento, aperfeiçoando os processos participativos. Brugué (2008) enfatiza que, para a gestão não fracassar na organização da participação cidadã, é necessário definir uma estratégia de relação com os outros departamentos, visando identificar as dificuldades da transversalidade e ações explícitas para enfrentá-las. Navarro (2008) sugere organizar as oportunidades de participação de maneira que viabilizem a articulação de interesses e demandas dos cidadãos com o trabalho de representação de interesses das autoridades públicas eleitas nos processos eleitorais. Navarro, Cuesta e Font (2009) recomendam adotar a complementaridade de distintos espaços participativos em cada contexto, de acordo com diferentes tipos de público, evitando que uns mecanismos atrapalhem os outros. Minimizar ao máximo os vieses participativos produzidos pelo modelo de base associativa, que privilegia maior participação de certas associações em alguns espaços participativos, para ampliar a participação de atores diferentes nesses espaços, evita que sempre participem as mesmas pessoas e diminui a invisibilidade dos mecanismos participativos, divulgando-os. Sierra e Moreno (2011) propõem adotar as tecnologias de informação e comunicação (TICs) como uma das ferramentas para fomentar a participação e o desenvolvimento local, contribuindo para reconstruir o capital social, cultural e intelectual de uma determinada comunidade. 
Geli (2011) propõe identificar os coletivos específicos que se encontram em situação de risco de exclusão e que não estão representados suficientemente nos processos participativos, como jovens, idosos, imigrantes, mulheres, comunidades indígenas, minorias e camponeses, para incorporar mecanismos concretos que os incluam socialmente em cada território, além de desenvolver estratégias para mobilizar os jovens e as pessoas com menos recursos financeiros para participação nos mecanismos participativos, considerando a baixa participação deste público nestes espaços. Seller (2008) recomenda facilitar o acesso à participação cidadã não somente no uso de serviços, mas também na elaboração, gestão, execução e avaliação de políticas e programas, recuperando o protagonismo dos cidadãos, permitindo sua participação em decisões significativas para eles, promovendo uma progressiva socialização coletiva de desenvolvimento local, vitalizando o capital social dos municípios, potencializando os recursos humanos e enriquecendo o debate político.

A participação também pode ser vista como ação que pode ser planejada, projetada e orientada por regras e procedimentos acordados e implantados. Nessa direção, Brugué (2008) considera que, antes de iniciar o debate sobre um programa, plano, peça legislativa etc., deve-se apresentar o marco de referência do debate, que consiste em explicitar os eixos básicos que se quer impulsionar, os limites do debate, as linhas políticas de partida, os aspectos que serão discutidos e que representam uma opção política que não se quer deixar de assumir, explicando-os com a maior clareza aos participantes, sem travar debates eternos ou caóticos, definindo as regras e os prazos para o debate. $O$ autor propõe explicar os conteúdos básicos do debate à população e a importância do tema por meio de estratégias de comunicação, como mensagens, artigos, entrevistas, produção de materiais para a divulgação, através de meios de comunicação, logotipos, webs, banners, anúncios etc., adequando-os às características dos diferentes públicos a quem se destina tal explicação. Sugere ainda que os responsáveis públicos avaliem as contribuições nas reuniões e decidam quais serão incorporadas, justificando-as, documentando-as e divulgando-as aos participantes, para que tenham explicações sobre o que foi feito com as opiniões e contribuições, considerando-as, para que não se torne apenas um ritual participativo sem efeitos práticos.

De forma complementar aos planos e projetos sobre participação, é preciso pensar nos elementos necessários à operacionalização de um processo participativo. Gramberger (2011) avalia que a informação, a consulta e a participação ativa exigem recursos, tempo, experiência e dinheiro, como qualquer atividade da administração pública. Portanto, recursos precisam ser dispostos à participação cidadã, pois não o fazer pode gerar custos de curto prazo mais elevados, a exemplo das políticas públicas fracassadas e de longo prazo, devido à sua perda de confiança, legitimidade e eficácia. Também preocupados com esses recursos necessários à participação, Sierra e Moreno (2011) consideram que adotar modelos de integração e planejamento de equipamentos públicos às necessidades locais de desenvolvimento favorece maior efetividade, sustentabilidade e apropriação equitativa.

Ao entender a participação como valor, é fundamental o investimento em valores humanos que deem sustentação a valores participativos. É nesse sentido que Geli (2011) recomenda a adoção do princípio de justiça social, que se sustenta em valores como equidade, igualdade, respeito à diversidade, acesso à proteção social, inclusão e aplicação de direitos humanos para superar os limites de cidades fragmentadas por barreiras físicas, ideológicas, culturais, mentais, sociais e econômicas, as quais favorecem a permanência da exclusão e desigualdade e a proliferação de racismos desumanizadores das relações. Isso se faz necessário para que o exercício da cidadania ativa nos processos deliberativos se converta em uma possibilidade de transformação social voltada para a equidade, sistematização de critérios, priorização de propostas que diminuam desigualdades e melhorem a qualidade de vida em sociedade. 


\section{CONSIDERAÇÕES FINAIS}

As discussões desenvolvidas neste ensaio permitem levantar algumas considerações sobre as contribuições da experiência espanhola para o desenvolvimento do tema da participação cidadã local. Uma delas é que o termo "participação cidadã" é abordado como fenômeno criado ou fomentado pelas pessoas que exercem o comando da representação democrática. Ou seja, observa-se que preponderam ações e decisões dos cidadãos via mecanismos participativos criados pela administração pública local. As ações de iniciativa da população sem intervenção de representantes políticos são bem menos frequentes. Uma segunda consideração a ser destacada é que a participação não é vista como mecanismo de transformação ou de mudança social, mas sim como mero mecanismo de participação no sistema representativo de governo; como algo que complementaria o sistema representativo, não mais que isso. A participação cidadã não ultrapassaria, assim, os limites e os objetivos na ambiência da representação.

Geli (2011) é um dos autores que tangenciam a falta de participação como mecanismo de mudança social, ao aprofundar a crítica no plano econômico e ao considerar que os espaços participativos, principalmente num contexto de globalização capitalista ou neoliberal, aumentam a complexidade do significado da participação cidadã. Nesse contexto, um princípio basilar que pode ser estabelecido é o de que a participação cidadã deve ser compreendida como qualidade associada à emancipação; a participação, assim, afasta-se de pensamentos associados a modelos ou estruturas. Dentro dessa compreensão, é possível refletir a respeito da pergunta formulada para este ensaio: como as contribuições teóricas obtidas da experiência espanhola sobre o tema da participação cidadã contribuem para a compreensão da articulação do protagonismo popular na condução de políticas públicas e sociais locais? Como exposto, essas contribuições são difusas e plurais, mas a passagem pela literatura espanhola permitiu reuni-las e viabilizou uma reflexão conjunta do potencial que elas oferecem.

$\mathrm{O}$ aspecto histórico-cultural é componente estratégico em busca de acepção para participação cidadã, algo também pouco abordado nos estudos sobre o tema. Vale, então, citar novamente Geli (2011), que procura entender a participação cidadã a partir de interesse relativamente antropológico, ao estudar o fenômeno da participação em uma rede familiar local indígena, no que nota valores culturais participativos baseados no respeito mútuo, no reconhecimento pelo outro, em legitimação e em relações horizontais. Geli (2011) busca desenvolver, assim, uma noção de participação intercultural.

A participação é possibilidade de intervenção do cidadão na política, como ressaltam Falck e Yáñes (2011), mas também pode ser usada como instrumento de dominação e exclusão, como denuncia Chavez (2011), alertando que algumas definições de participação cidadã podem esconder intenções não condizentes com o significado de participar. Nesse debate, insere-se o dos níveis de participação, já que a participação em níveis muito baixos pode servir para restringir deliberadamente a participação. A participação em níveis muito baixos pode ser confundida com pseudorrepresentação e, em níveis mais elevados, tenderia aos valores da autogestão.

Os resultados obtidos com a introdução da participação por meio de legislação não podem ser muito animadores, como constatou o próprio Navarro (2000). A participação vista como conduta que pode ser animada ou obrigada mediante lei é visão objetivada, que não considera a participação cidadã como valor que está associado ao interesse das pessoas em se organizarem em sociedade, ou seja, em torno de interesses comuns. Desde a pesquisa de Navarro (2000), legislações estabelecendo a participação como conduta a ser seguida nas instituições representativas têm crescido em diversos países. No entanto, isso não quer dizer que essas legislações tenham contribuído para o desenvolvimento da consciência participativa nos cidadãos. 
Navarro, Cuesta e Font (2009) também investigam um fator que influencia na participação, que é a desconfiança na eficácia de seus mecanismos. Embora alguns cidadãos utilizem essa justificativa, a confiança é razoavelmente alta entre os demais e aqueles que os conhecem, valorizando-os melhor que o restante da população, ainda que possa haver variações e situações inversas de um município para o outro. A desconfiança atua contra a participação de algumas pessoas, porém não parece ser um fator explicativo fundamental nos resultados das pesquisas desses autores. A confiança é outro elemento-chave no conceito de participação. O nível de confiança nas relações pessoais em determinada comunidade aumenta o nível de participação. Quando se trata de participação, a primeira noção que emerge é de reunião de pessoas para discussão de determinado problema ou ação. Mas, ações individuais também podem ser consideradas participação, como um telefonema para a prefeitura, por exemplo, para tratar de determinado problema, bem como participação em petições, contato pessoal com representantes políticos etc. As associações, com diferentes características e objetivos, exercem impacto na participação cidadã.

Dois aspectos importantes ligados à gestão também aparecem como impactantes na participação cidadã. Trata-se do tipo de gestão adotado e do estilo pessoal do gestor. A forma de gestão adotada pelos gestores públicos de determinada localidade influencia na característica e na intensidade da participação cidadã, como estudou Chavez (2011). Essa forma de gestão pode estar mais próxima à ideia do cidadão como consumidor de bens e serviços públicos, ideia oriunda da ideia de mercado.

A partir do confronto teórico entre diferentes contribuições oriundas da experiência espanhola sobre o tema em tela, pode-se afirmar que o objetivo deste ensaio, de identificar e discutir contribuições da experiência espanhola para o desenvolvimento do tema participação cidadã local, foi atingido. Com base nesses resultados, a discussão aqui apresentada permite evidenciar conceitos distintos e complementares, que revelam elementos que sintetizam a complexidade da participação cidadã local, como:

1. A qualidade humana associada à emancipação: as iniciativas cidadãs associadas a práticas de autogestão de determinados espaços públicos, independentes de iniciativas institucionais de participação, vão ao encontro dessa natureza emancipatória da participação (BARBARRUSA et al., 2011).

2. O foco na mudança da realidade social: a participação está, assim, associada à forma de organização do Estado, à cultura política, à cidadania, ao desenvolvimento humano e social, como destaca Marchioni (2006), ao defender a participação cidadã como condição essencial a qualquer mudança social.

3. A integração entre participação, gestão e desenvolvimento: de acordo com Pindado (2012), a participação cidadã pode ser compreendida como um leque de iniciativas associadas à democracia participativa. O propósito é o desenvolvimento local através da incorporação da comunidade à política. São ideias que se aproximam de valores associados à autonomia e à política, e cujas iniciativas podem ser tanto comunitárias quanto institucionais. A visão de Pindado (2012) contempla a incorporação da comunidade ao significado de política, e não meramente à representação política.

4. Os valores histórico-culturais locais: Geli (2011), a partir de estudos com indígenas chilenos e descendentes de europeus, que cultivam em suas inter-relações princípios de participação cidadã, incorpora valores histórico-culturais associados às relações sociais entre grupos culturalmente diferentes, linha que também é tan- 
genciada por Morales (2005), numa visão sobre a participação desmembrada entre política e cultura. A participação cidadã, segundo o autor, inclui a participação em espaços externos ao espaço da representação política. Portanto, a participação é uma produção social, histórica e cultural, cultivada a partir de relações.

5. As expressões minoritárias: Geli (2011) destaca a necessidade de identificação de espaços sociais específicos em situação de risco e exclusão, visando à sua inclusão social por meio da participação. $O$ autor vislumbra o desenvolvimento de estratégias de participação com o objetivo de aumentar a participação dessas comunidades específicas nos mecanismos participativos.

6. As relações horizontais e de confiança: Geli (2011), com base em pesquisas, salienta valores culturais participativos pautados no respeito mútuo, no reconhecimento do outro, na legitimação e em relações de confiança. Dessa forma, considera a diversidade e a pluralidade cultural na comunidade, e não um simples pensar a participação cívica, por exemplo, como mero mecanismo de melhoria da administração pública, conforme adverte Chavez (2011).

7. A intervenção no sistema representativo: a participação é vista por Brugué (2007), por exemplo, como reforço dos mecanismos da democracia. Em sentido parecido, Borrel (1998) entende a participação como possibilidade de intervenção do cidadão na administração pública, mas sem sua integração nas estruturas burocráticas. Entretanto, valores associados à autonomia, à história, à cultura, à emancipação, à criação e à ação humana, evidenciados por outros autores neste trabalho, remetem à participação para além da complementariedade à representação política; participação associada à democracia como valor, que antecede estruturas e sistemas político-representativos.

8. As ideias de dominação e exclusão que possam permeá-la: Chavez (2011) é um autor que chama a atenção para a permanência da dominação e da exclusão social em espaços aparentemente participativos. Ao que parece, faz uma crítica à representação e à ideia de decisão pela maioria, que desconsidera sujeitos historicamente marginalizados, nos campos do gênero, origem étnica, classe social, ideologia política, idade, sexualidade, entre outros.

9. A participação cidadã ocorre de forma individual ou coletiva: Navarro, Cuesta e Font (2009) destacam o que chamam de modalidades políticas, que afloram individualmente, como um simples contato de um cidadão com o vereador, assinatura de uma petição ou participação em manifestações e greves.

10. A precedência aos tipos de gestão e modos pessoais de gestão: a participação é influenciada pelo tipo de administração praticada pelos representantes políticos, como observa Chavez (2011). De um lado, é influenciada pelo administrador público com visão tendente a ideias de mercado, em que reside, por exemplo, a visão de cidadão como cliente. De outro lado, é influenciada pelo administrador público que procura aproximação mais estreita com a sociedade, por meio da implantação de mecanismos que busquem essa aproximação. Quando planejados e orientados por regras e procedimentos, tais aspectos devem ser definidos por meio de participação. Gramberger (2011) chama a atenção para o fato de que o processo de participação exige recursos, tempo, experiência e dinheiro, assim como qualquer atividade formal da administração pública requer planejamento. 
Em conjunto, esses aspectos revelam parte da complexidade que permeia a participação cidadã local com base na experiência espanhola. De forma geral, os estudos e reflexões apresentados neste ensaio servem para ilustrar a difusão de entendimentos que envolvem o tema da participação cidadã. Mostram a profusão de ideias que habitam diferentes visões do que vem a ser participar como cidadão em determinada localidade. Assim, pode-se afirmar que há uma pluralidade e diversidade de aspectos que orbitam o tema participação cidadã local, com potencialidades significativas para seu desenvolvimento teórico.

\section{REFERÊNCIAS}

BARBARRUSA, V. G. et al. Funcionamiento institucional de los Presupuestos Participativos: la articulación de los PPs con los mecanismos institucionales de la administración local. In: FALCK, A.; YÁÑEZ, P. P. (Ed.). Democracia participativa y presupuestos participativos: acercamiento y profundización sobre el debate actual. Manual Docente de la Escuela de Políticas de Participación Local. Redes para el Fortalecimiento de Capacidades de Gestión de Políticas Públicas Locales de Participación Ciudadana (PARLOCAL). España: Centro de Ediciones de la Diputación de Málga (CEDMA), jun. 2011. Cap. 14, p. 311-340.

BAVA, S. C. Mitos e realidades sobre a inclusão social, participação cidadã e desenvolvimento local: uma discussão sobre contextos e conceitos. In: Foro temático regional gobernabilidad para el empoderamiento de los pobres, 2., 2002, Lima. Anais... Lima, 2002. Disponível em: <http://ftp.Ina.br/users/ mabans/misc/on_is/contexto.htm>. Acesso em: 16 jul. 2015.

BERGANTIÑOS, N.; IBARRA, P.; MARTINEZ, J. Participación, cultura política y sostenibilidad. Barcelona: Hacer, 2011.

BIAGIONI, D.; ALEMANY, C. Municipalismo, movimientos ciudadanos, redes nacionales e internacionales en torno a la democracia directa. In: FALCK, A.; YÁÑEZ, P. P. (Ed.). Democracia participativa y presupuestos participativos: acercamiento y profundización sobre el debate actual. Manual Docente de la Escuela de Políticas de Participación Local. Redes para el Fortalecimiento de Capacidades de Gestión de Políticas Públicas Locales de Participación Ciudadana (PARLOCAL). España: Centro de Ediciones de la Diputación de Málga (CEDMA), jun. 2011. Cap. 4, p. 65-92.

BONETT, M. A. Participación ciudadana en el desarrollo local. s.d. Disponível em: <http:// www.bantaba.ehu.es/formarse/ficheros/ view/Gu\%C3\%AdaParticipaci\%C3\%B3n_ Ciudadana_en_el_ Desarrollo Local\%20observaciones.pdf?revision_ id=79394\&package_id=79281> Acesso em: 3 jun. 2012.

BORREL, F. Iniciativa y colaboración particular. En el Funcionario Municipal. Ayuntamiento de Madrid. España, 1998.

BRUGUÉ, Q. T. La participación en el ámbito local: ¿una crisis de crecimiento? Revista Temas para el Debate, n. 152, jul. 2007, p. 64-67.

Modernizar la administración a través de la participación: la experiencia de la Generalitat de Catalunya. Revista Internacional de Organizaciones (RIO), n. 1, p. 39-53, dic. 2008.

CARR, R. España de la restauración a la democracia, 1875-1980. Barcelona: Ariel, 1983.

CHAVEZ, D. Polis y Demos: el marco conceptual de la democracia. In: FALCK, A.; YÁÑEZ, P. P. (Ed.). Democracia participativa y presupuestos participativos: acercamiento y profundización sobre el debate actual. Manual docente de la Escuela de Políticas de Participación Local. Redes para el Fortalecimiento de Capacidades de Gestión de Políticas Públicas Locales de Participación Ciudadana (PARLOCAL). España: 
Centro de Ediciones de la Diputación de Málga (CEDMA), jun. 2011. Cap. 1, p. 23-45.

FALCK, A.; YÁÑEZ, P. P. (Ed.). Democracia participativa y presupuestos participativos: acercamiento y profundización sobre el debate actual. Manual Docente de la Escuela de Políticas de Participación Local. Redes para el Fortalecimiento de Capacidades de Gestión de Políticas Públicas Locales de Participación Ciudadana (PARLOCAL). España: Centro de Ediciones de la Diputación de Málga (CEDMA), jun. 2011.

FERNÁNDEZ, E. G.; OLIVARI, L.; YÁÑEZ, P. P. La democracia en acción: participación de la ciudadanía en la gestión pública. Metodologías participativas y presupuestos participativos. In: FALCK, A.; YÁÑEZ, P. P. (Ed.). Democracia participativa y presupuestos participativos: acercamiento y profundización sobre el debate actual. Manual Docente de la Escuela de Políticas de Participación Local. Redes para el Fortalecimiento de Capacidades de Gestión de Políticas Públicas Locales de Participación Ciudadana (PARLOCAL). España: Centro de Ediciones de la Diputación de Málga (CEDMA), jun. 2011. Cap. 7, p. 149-178.

FONT, J. et al. Mecanismos de participación ciudadana en la toma de decisiones locales: una visión panorámica. In: CONCURSO DE ENSAYOS DEL CLAD "ADMINISTRACIÓN PÚBLICA Y CIUDADANÍA", 14., 2000, Caracas. Anais... Caracas, 2000. Tercer Premio.

BLANCO, I. ¿Qué hay detrás de la oferta de participación? El rol de los factores instrumentales e ideológicos en los mecanismos españoles de participación. Revista del CLAD Reforma y Democracia, Caracas, n. 31, p. 1-17, feb. 2005.

FUENTE, J. M. R. de la. Contra la participación: discurso y realidad de las experiencias de participación ciudadana. Política y Sociedad, v. 47, n. 3, p. 93-108, 2010.

GELI, J. B. El funcionamiento operativo de los
Presupuestos Participativos. In: FALCK, A.; YÁÑEZ, P. P. (Ed.). Democracia participativa y presupuestos participativos: acercamiento y profundización sobre el debate actual. Manual Docente de la Escuela de Políticas de Participación Local. Redes para el Fortalecimiento de Capacidades de Gestión de Políticas Públicas Locales de Participación Ciudadana (PARLOCAL). España: Centro de Ediciones de la Diputación de Málga (CEDMA), jun. 2011. Cap. 12, p. 261-279.

GRAMBERGER, M. Participación ciudadana: manual de la OCDE sobre información, consulta y participación en la elaboración de políticas públicas. Paris: Organización para la Cooperación y El Desarrollo Económicos (OCDE), 2006.

LENGLER, L. Uma análise do comportamento empreendedor e do processo decisional de presidentes de associações apícolas no Rio Grande do Sul. Revista de Administração da UFSM, Santa Maria, v. 1, n. 1, p. 153-170, jan./ abr. 2008.

MARCHIONI, M. Democracia participativa y crisis de la política: la experiencia de los países comunitários. Cuadernos de Trabajo Social, v. 19, p. 213-224, 2006.

MONTERO, A. Historia de la persecución religiosa en España, 1936-1939. Madrid: B.A.C., 1961.

MORALES, L. ¿Existe una crisis participativa? La evolución de la participación política y el asociacionismo en España. Revista Española de Ciencia Política, n. 13, p. 51-87, oct. 2005.

MORAIS, N. Más allá del presupuesto participativo: la participación como espacio de coordinación transversal de diferentes políticas públicas. In: FALCK, A.; YÁÑEZ, P. P. (Ed.). Democracia participativa y presupuestos participativos: acercamiento y profundización sobre el debate actual. Manual Docente de la Escuela de Políticas de Participación Local. Redes para el Fortalecimiento de Capacidades 
de Gestión de Políticas Públicas Locales de Participación Ciudadana (PARLOCAL). España: Centro de Ediciones de la Diputación de Málga (CEDMA), jun. 2011. Cap. 2, p. 47-52.

NAVARRO, C. J. Y. El sesgo participativo. Introducción a la teoría empírica de la democracia participativa. Papers 61, p. 1137, 2000. Disponível em: <http://ddd.uab.cat/ pub/papers/02102862n61/02102862n61p11. pdf>. Acesso em: 9 jun. 2012.

Participación local. Boletín Centro de Investigaciones Sociológicas (CIS), Madrid, $n$. 4, p. 1-9, 2008.

CUESTA, A. M.; FONT, F. J. Municipios

participativos? Participación política $\mathrm{Y}$ ciudadana en ciudades medias españolas. Madrid: Centro de Investigaciones Sociológicas (CIS), oct. 2009. (Opiniones y Actitudes, 62).

Partido Socialista Obrero Español (PSOE). Historia del Partido Socialista Obrero Español. 2015. Disponível em: <http://www. psoe.es//ambito/historiapsoe/docs/index. do?action=View\&id=460110 $>$. Acesso em: 22 jul. 2015.

PINDADO, F. La participación ciudadana es la vida de las ciudades. Gobierno del Ayuntamiento de Azuqueca de Henares, España, 2012. Disponível em: <http:// www.azuqueca.es/servicios/participacionciudadana>. Acesso em: 29 out. 2012.

SALVADÓ, F. J. R. A Guerra Civil Espanhola. Rio de Janeiro: J. Zahar, 2008.

SELLER, E. P. Mecanismos de participación ciudadana en los servicios sociales municipales: las realidades de la Región de Murcia. Cuadernos de Trabajo Social, v. 21, p. 7-25, 2008.

SIERRA, F.; MORENO, J. Nuevas tecnologías de la información para la democracia participativa y la ciudadanía digital. La propuesta de los telecentros. In: FALCK, A.; YÁÑEZ, P.P. (Ed.). Democracia participativa y presupuestos participativos: acercamiento y profundización sobre el debate actual. Manual Docente de la Escuela de Políticas de Participación Local. Redes para el Fortalecimiento de Capacidades de Gestión de Políticas Públicas Locales de Participación Ciudadana (PARLOCAL). España, Centro de Ediciones de la Diputación de Málga (CEDMA), jun. 2011. Cap. 10, p. 215-231.

SUBIRATS, J. Nuevos mecanismos participativos y democracia: promesas y amenazas. In: FONT, J. (Coord.). Ciudadanos y decisiones públicas. Barcelona: Ariel, 2001. p. 33-42. . Prólogo. In: BLANCO, I.; GOMÀ, R. (Coord.). Gobiernos locales y redes participativas. Barcelona: Ariel, 2002. p. 17-20.

TORCAL, M. Desafección institucional e historia democrática en las nuevas democracias. Revista SAAP, v. 2, n. 3, p. 591-634, ago. 2006. 